\title{
Infectious ulcerative colitis resulting in incomplete Reiter's syndrome
}

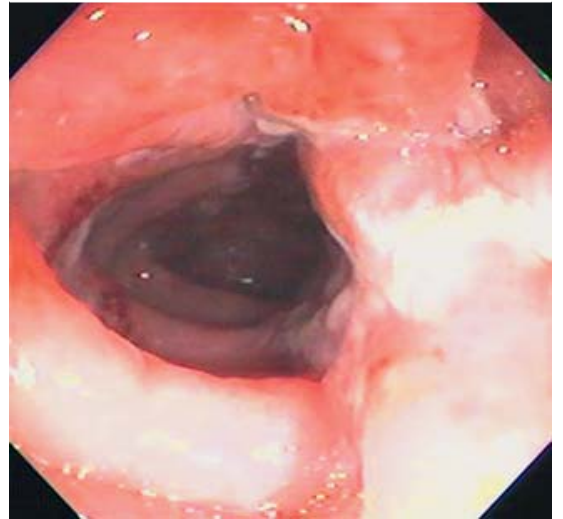

Fig. 1 A 20-year-old man presenting with a 3-week history of lower abdominal pain was found to have infective colonic ulcers on colonoscopic examination.

A 20-year-old man presented with a 3-week history of lower abdominal pain. He had self-limiting diarrhea for 3 days prior to this episode of pain. Findings from physical examination and laboratory tests were unremarkable. On ultrasound examination, an edematous sigmoid colon was noted. Colonoscopy revealed multiple large ulcers in the rectum and sigmoid colon ( Fig. 1). On histopathological examination, these lesions were confirmed as infective colonic ulcers ( $\bullet$ Fig. 2). The patient was treated with oral antibiotics and became asymptomatic.

He presented 10 days later with an episode of arthritis with bilateral involvement of the knee joints. Findings from X-ray and ultrasound examination of knee joints were normal. His laboratory data showed an elevated C-reactive protein (CRP) level of $9.8 \mathrm{mg} / \mathrm{dL}$ (normal $<0.5 \mathrm{mg} / \mathrm{dL}$ ), an elevated erythrocyte sedimentation rate (ESR) of $36 \mathrm{~mm} / \mathrm{h}$ (normal $0-22 \mathrm{~mm} / \mathrm{h}$ ), and normal serum uric acid levels. Tests for rheumatoid arthritis (RA) factor and antinuclear antibody (ANA) were negative. He responded well to injectable analgesics and was discharged. After 15 days, he developed a second episode of arthritis with bilateral involvement of the knee joints ( Fig.3), which responded well to injectable analgesics, oral sulfasalazine, and physiotherapy.

This case is interesting for several reasons. Although reactive arthritis is usually described as a sequela of infective diarrhea

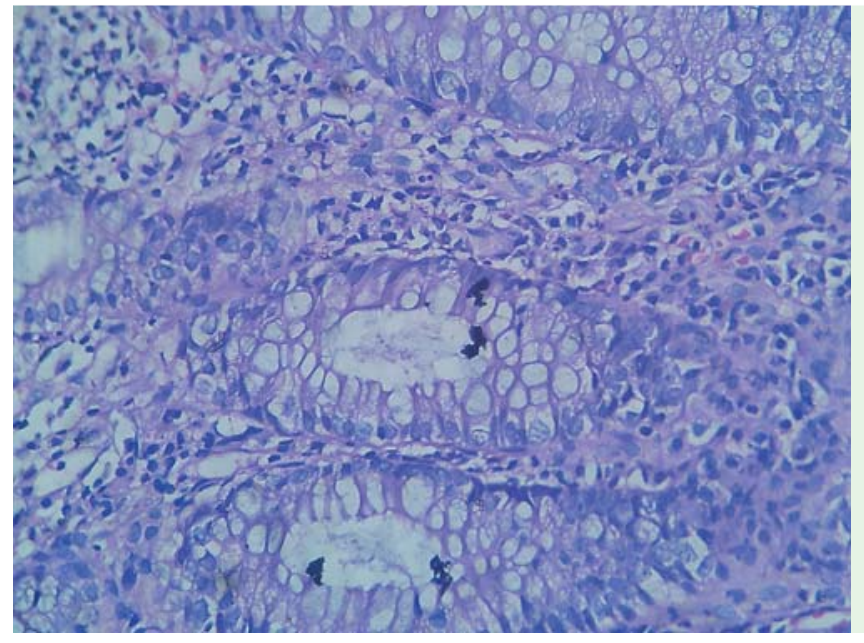

Fig. 2 Histopathological examination confirmed that the lesions were infective colonic ulcers.

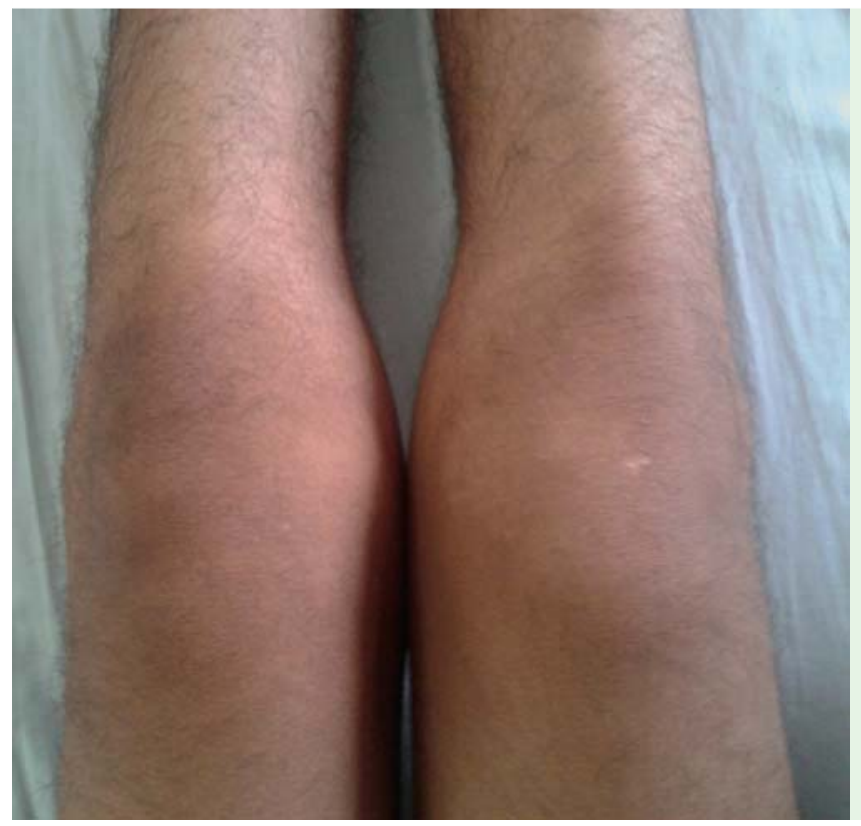

Fig. 3 Arthritis with bilateral involvement of the knee joints, later in the same patient.

(stool culture positive for bacteria), this is the first demonstration of an association between infective colonic ulcers and reactive arthritis. Reactive arthritis is a rheumatoid factor-seronegative, HLA-B27linked arthritis often precipitated by genitourinary or gastrointestinal infections [1]. The most common triggers are intestinal infections with Salmonella, Shigella, or Campylobacter, and sexually transmitted infections with Chlamydia trachomatis or Neisseria gonorrhea [2].

The classic syndrome is a triad of symptoms, including urethritis, conjunctivitis, and synovitis [3]. Reactive arthritis is usually unilateral; however, in our patient there was bilateral involvement of knee joints, without ocular or urethral involvement.

To conclude, reactive arthritis is a selflimiting disease with significant morbidity and can also occur as a sequela to infective colonic ulcers. Diagnostic criteria for reactive arthritis exist, but data now suggest that new criteria may be needed [3]. A high degree of suspicion and early diagnosis are key to managing this condition.

Endoscopy_UCTN_Code_CCL_1AD_2AZ 
Competing interests: None

\section{Jay Toshniwal' ${ }^{1}$, Romesh Chawlani ${ }^{1}$, Mukesh Bang ${ }^{1}$, Sachin Kale ${ }^{2}$}

${ }^{1}$ Department of Gastroenterology and Hepatology, Max Superspeciality Hospital, Aurangabad, Maharashtra, India

2 Department of Pathology, Max Superspeciality Hospital, Aurangabad, Maharashtra, India

\section{References}

1 Hill Gaston JS. Reactive arthritis and undifferentiated spondyloarthritis. In: Firestein GS, Budd RC, Gabriel SE et al., eds. Kelley's Textbook of Rheumatology. 9th edn. Philadelphia: Saunders; 2013: 1221-1231

2 Hill Gaston JS, Lillicrap M. Arthritis associated with enteric infection. Best Pract Res Clin Rheumatol 2003; 17: 219-239

3 Carter J, Hudson A. Reactive arthritis: clinical aspects and medical management. Rheum Dis Clin North Am 2009; 35: 21 - 44
Bibliography

DOI http://dx.doi.org/

10.1055/s-0034-1391654

Endoscopy 2015; 47: E229-E230

(c) Georg Thieme Verlag KC

Stuttgart · New York

ISSN 0013-726X

Corresponding author Jay Toshniwal, MD

Max Superspeciality Hospital Aurangabad

431005 Maharashtra

India

Fax: +91-11-42251004

drjaytoshniwal@yahoo.com 